Supporting information for:

\title{
Quantifying Specific Ion Effects on the Surface Potential and Charge Density at Silica Nanoparticle-Aqueous Electrolyte Interfaces
}

Tobias A. Gmür, Alok Goel and Matthew A. Brown*

Laboratory for Surface Science and Technology, Department of Materials, ETH Zürich, CH-8093 Zurich, Switzerland

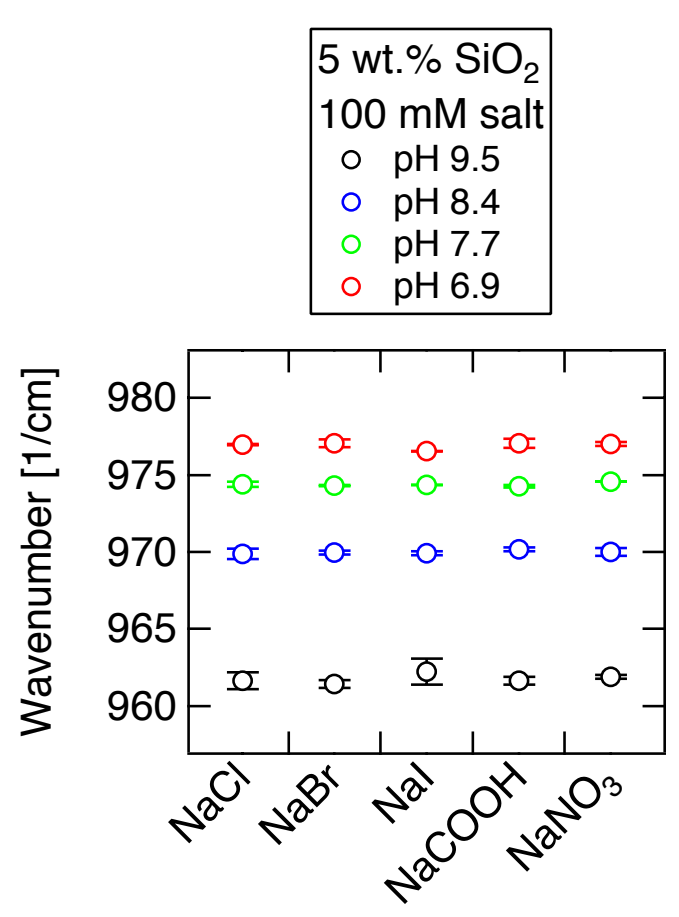

Figure S1. ATR-FTIR band position of the $\mathrm{Si}-\mathrm{O}$ stretch vibration of neutral silanols, $\equiv \mathrm{Si}-\mathrm{OH}$, for 5 wt.\% colloidal silica in $100 \mathrm{mM} \mathrm{NaCl}, \mathrm{NaBr}, \mathrm{Nal}, \mathrm{NaCOOH}$ and $\mathrm{NaNO}_{3}$. 